\title{
Geomechanics of overworked mine working support resistance in the laminal massif of soft rocks
}

\author{
Iryna Kovalevska ${ }^{*}$, Hennadii Symanovych ${ }^{2}$, Jacek Jarosz ${ }^{3}$, Mykhailo Barabash ${ }^{4}$, and \\ Oleksandr Husiev ${ }^{5}$ \\ ${ }^{1}$ Dnipro University of Technology, Department of Mining Engineering and Education, 19 \\ Yavornytskoho Ave., 49005 Dnipro, Ukraine \\ ${ }^{2}$ Dnipro University of Technology, Department of Labour Protection and Civil Safety, \\ 19 Yavornytskoho, 49005 Dnipro, Ukraine \\ ${ }^{3}$ Mineral and Energy Economy Research Institute of the Polish Academy of Sciences, Division of \\ Mineral Resource Acquisition, 7 Wybickiego St., 31-261 Krakow, Poland \\ ${ }^{4}$ LLC "DTEK Energy", Department on Coal Production, 57 Lva Tolstoho St., 01032 Kyiv, Ukraine \\ ${ }^{5} \mathrm{MM}$ “Dniprovske”, PJSC “DTEK Pavlohradvuhillia”, 76 Soborna Ave., 51400 Pavlohrad, Ukraine
}

\begin{abstract}
The relevant issues of ensuring trouble-free mining operations on the underlying horizons, which are partially or fully overworked are studied in this paper. The problem has been solved using the example of a laminal massif of the Western Donbas soft rocks; complicating factors were taken into account: water-cut, fracturing, and the rheological properties manifestation. The model, proposed for calculation, has been substantiated in view of geomechanics, as well as the finite element method has been chosen to obtain the stress-strain state of the adjacent massif and support. At the first stage, mine observations of the state of mine working planned for overworking have been conducted and analysed. At the second stage, a computational experiment has been conducted in the most difficult areas. The stresses fields have been analysed according to vertical, horizontal and stresses intensity components of the soft rocks laminal massif, as well as their distribution curves for the recommended and basic fastening options. It has been proved that the recommended parameters of the fastening structure provide repair-free mine working maintenance for the entire exploitation period with account of overworking. Recommendations have been developed for mining the seam $C_{6}$ in M.I. Stashkova Mine, DTEK Pavlohradvuhillia PJSC.
\end{abstract}

\section{Introduction}

The research topic relevance is conditioned by the necessity of effective solving a number of production tasks related to ensuring trouble-free mining operations at the underlying horizons, which were partially or fully overworked in previous or current periods of the enterprise's activity [1]. For example, in the Western Donbas (Ukraine) conditions, the issues of coal mining intensification and the completeness of the coal reserves extraction

\footnotetext{
* Corresponding author: kovalevska i@yahoo.com
} 
are very relevant. The first direction is related to the simultaneous development of two or three coal seams within one mine field site $[2,3]$; the second direction is related to the reserves extraction in various kinds of protecting pillars left over from mining operations of previous periods [4]. These directions, which are not related at first glance, are united by the common task of reliable mine workings maintenance while conducting stope works on overlying horizons. In the Western Donbas conditions, the mining-and-geological, as well as mining-engineering situation is complicated by the fact that mining operations must be carried out in a laminal massif of soft rocks, exposed to intensive weakening factors influence, namely water-cut, fracturing and rheology. Therefore, the successful task solution requires, first of all, a multifaceted geomechanical substantiation, based on the studying the state of overworked massif and the mine working support.

The indicated tasks are far from new, hence, a sufficient number of works has been devoted to their study and solution. For example, the works [5-7] are devoted to the study of weakening areas influence of parting rocks during joint and downward coal seams mining. The authors created a database for revealing weakening areas along the extraction panel length for calculating the fastening and security systems of the preparatory mine workings based on the conduction and analysis of multivariate experiments [8-10]. The research continuation is to determine a relation between the deformation-strength characteristics of collapsed rocks and the "support - security" system elements [11], which is the basis for optimizing the parameters of mine working maintenance [12 - 14].

\section{Research objective}

The ultimate purpose of research is the development of practical recommendations for maintaining the underlying mine working, (steep-dipping ventilation crosscut No. 1 (SVC No. 1), driven in the seam $C_{5}+C_{5}{ }^{l}$ bottom), when extracting coal reserves of the overlying seam $C_{6}$ within the boundaries of the protecting pillar, which was previously designed specifically to protect SVC No. 1 from the consequences of its overworking. The substantiation of the planned stope works parameters for a more complete reserves extraction is based, first of all, on the studying stress-strain state (SSS) of the adjacent massif and SVC No. 1 support: the results of assessing the state of the mine working fastening structure by analytical methods in combination with mine instrumental observations will serve as the basis for making such a technical decision (taking into account measures to strengthen the support) or rejecting it.

From the point of view of geomechanics, the task of the laminal massif SSS calculation of the soft rocks to a height of at least $60-65 \mathrm{~m}$ is quite difficult in itself. Moreover, the difficulties are aggravated by the necessity to model both the stope face (with equipment) along the seam $C_{6}$ and the "small-sized" elements of the SVC No. 1 support. An adequate reflection of the studied mining-and-geological and mining-engineering situation is possible only by numerical research methods, among which the finite element method (FEM) is most widely used (due to its advantages). It was accepted for application, taking into account some assumptions, the main of which is based on an assessment of the stope works influence along the seam $C_{6}$ on the state of the SVC No. 1 in case of overworking.

The presence or absence of the overwork influence on the rock pressure manifestations in the mine working under study is a key assumption on which the reliability of the computational experiment results substantially depends.

On the other hand, the assumption about the absence of the overwork influence on the state of the SVC No. 1 enables to consider this mine working as a single one outside the zone of the stope works' influence and significantly simplify the geomechanical model. Thus, a well-founded opportunity arises of:

- reducing the height of the model by more than 2 times with the exception of a number 
of the most remote lithotypes in the roof of the seam $C_{5}+C_{5}{ }_{5}$;

- there is no need to model the longwall face with sections of powered support located in it along the seam $C_{6}$;

- a reflection of disturbed rocks characteristic zones in the mined seam $C_{6}$ roof is also excluded;

- it becomes possible to replace the three-dimensional statement of a problem with a two-dimensional one with consideration only in a vertical section of $Y Z$, perpendicular to the longitudinal axis $X$ of the SVC No. 1.

All these simplifications are completely substantiated by the existing principles for solving geomechanics problems, which enables to significantly save computational resource and redirect it to the "small" parts modelling of the SVC No. 1 fastening structure; the action also increases the final results reliability of the computational experiment on the studying the SSS of mine working support.

On the other hand, accounting the possible influence of the SVC No. 1 overwork also increases the results reliability of calculating the SSS in terms of studying the displacement process of the coal-overlaying formation during the stope extraction of the seam $C_{6}$. When the longwall face moves on the rise of the seam $C_{6}$, the frontal bearing pressure is also propagated into the seam bottom with a steady decrease in stresses concentrations along the depth of a parting [15]. The thickness of a parting (seams $C_{6}$ and $C_{5}+C_{5}{ }^{l}$ ) varies in the main range of $26-28 \mathrm{~m}$ and does not allow to unambiguously judge about the possibility of bearing pressure to reach the border rocks of the SVC No. 1. Therefore, there is a probability to enhance the load on the fastening structure of mine working, the consideration of which also helps to increase the results reliability of the computational experiment. In regard to the above, it should be noted that an increase in the load on the mine working support by several tens of percent can significantly affect its stability, namely, such a residual influence of the front bearing pressure (caused by the seam $C_{6}$ extraction) is quite possible in the mining-engineering situation under study.

The following methodological approach is proposed for agreeing the advantages of a single mine working modelling with account of the possible impact of its overworking. At the first stage, the real state of the SVC No. 1 is studied by measuring the final mine working dimensions for a current period of time. A general assessment of its performance characteristics is given, and the least stable areas are identified with the determination of reserves for the possible worsening of mining-and-geological situation. At the second stage, the proposed fastening structure is modelled with strengthening the basic (frame) support with a set of resin-grouted roof bolts (in the least stable areas). In addition, the reserves are assessed for increasing the support resistance reaction in case of worsening the mining-andgeological conditions for maintaining the SVC No. 1. At the third stage, the basic support structure is modelled and a comparative analysis of its state is made relative to the strengthened fastening system. Therewith, all the revealed reserves (in percentage terms) of the load-bearing capacity of support are compared under the influence of overworking, on the basis of which practical recommendations are developed on the differentiated strengthening of the fastening structure along the length of the SVC No. 1.

\section{Solution to a problem}

The first stage is in conducting and analysing mine observations of the state of mine working planned for overworking. Before to start extraction of the protecting pillar, the SVC No. 1 can be considered as a single mine working, since: the previously mined-out areas of the seam $C_{6}$, which are located near the protecting pillar, have insignificant influence due to the remoteness along the seam strike of the stope works boundaries of past periods; considerable thickness of a parting between $C_{6}$ and $C_{5}+C_{5}{ }^{l}$; a sufficiently long 
period of time interval passed after the extraction completion of the seam $C_{6}$ adjacent areas, during which, due to rheological processes, "smoothing" occurred of the rock pressure anomalies. Therefore, the observed rock pressure manifestations are related only to the adjacent massif behaviour, and it affects the state of the SVC No. 1 of the seam $C_{5}$ according to measurements data made by the mine surveying service.

Fig. 1 shows the graphs of changes along the mine working of the main geometric parameters of the SVC No. 1 of the seam $C_{5}$, to which can be attributed the current values of its height $h_{w}$, width $B_{w}$ and the value of the residual section $S$. It must first be noted that technical and technological standards, as well as the safety rules requirements for mine operation, are not violated in any of the analysed parameters. Nevertheless, when mining-out the protecting pillar along the seam $C_{6}$, less stable areas along the length of mine working may appear, which should be strengthened in advance to ensure further stable operational state of the SVC No. 1 of the seam $C_{5}$.

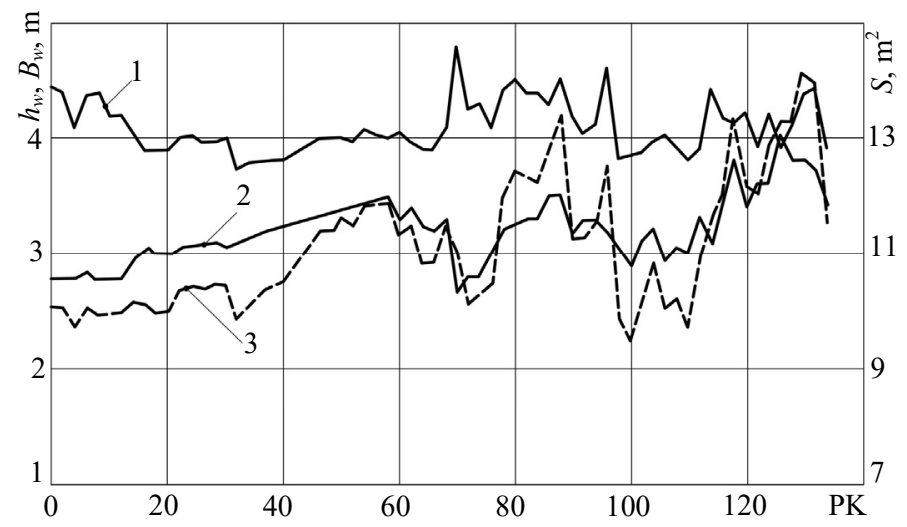

Fig. 1. The measurement results of changes in the geometric parameters of the SVC No. 1 cross section of the seam $C_{5}: 1$ - width $B_{w} ; 2$ - height $h_{w} ; 3$ - area $S$ of the residual mine working section.

The current value of mine working width varies in the main range of $B_{w}=3.9-4.2 \mathrm{~m}$, which corresponds to the sides convergence (for the entire period of exploitation) at the level of $400-700 \mathrm{~mm}$. This convergence value exceeds the permissible lateral yielding property of the frame (100 $\mathrm{mm}$ from each side of mine working), however, the joist couplings are in a satisfactory condition and there is no evident plastic bending and buckling of the prop stays of the frame support. All the noted circumstances as a whole lead to the conclusion that the mine working width is maintained at a level sufficient to ensure its reliable functioning.

The main range of changes in the current height of the SVC No. 1 of the seam $C_{5}$ is $3.0-3.2 \mathrm{~m}$, which corresponds to the rocks convergence of the roof and bottom at the level of $600-800 \mathrm{~mm}$. The maximum convergence of the roof and bottom is observed in the area of PK0 - PK12 (up to $1000 \mathrm{~mm}$ ) and PK70 - PK74 (up to $1100 \mathrm{~mm}$ ). Obviously, the main role in the value of total convergence is played by the heaving process of bottom rocks of the SVC No. 1 of the seam $C_{5}$, where argillite and siltstone with medium thickness periodically occur, which, when moisture-saturated, lose compression resistance up to $5.4 \mathrm{MPa}$ and $6.2 \mathrm{MPa}$, respectively; moreover, argillite is characterized as intensely heaving. Nevertheless, in some areas of mine working, a slight flattening of the frame cap board is observed, especially when the yielding joists actuate without exhausting the design value $(300 \mathrm{~mm})$ due to the fact that ends of the cap board and prop stays get wedged.

In general, according to the current height $h_{w}$ factor of the SVC No. 1 of the seam $C_{5}$, mine working is in a quite operational state. 
According to the factor of the cross section residual area $S$, ventilation requirements indicate the minimum permissible value of $6.0 \mathrm{~m}^{2}$. From the point of view of this condition, the entire mine working length is in a satisfactory state:

- the main part of the crosscut length has a range of variation of $S=10.5-11.5 \mathrm{~m}^{2}$ or more, which is by $1.75-1.92$ times exceeds the minimum permissible value;

- in some mine working areas (PK3 - PK5, PK31 - PK33, PK98 - PK101, PK109 PK111), the residual section is $S=9.49-9.88 \mathrm{~m}^{2}$, which, nevertheless, is by $1.58-1.65$ times higher than the minimum permissible one.

Thus, the general conclusion regarding the analysed geometric parameters is that the SVC No. 1 of the seam $C_{5}$ is in a satisfactory operational state.

At the same time, it should not be ignored the possible poorly predicted complications of mining-and-geological conditions for maintaining the SVC No. 1 of the seam $C_{5}$. These complications may not be related to mining the protecting pillar of the seam $C_{6}$. If to consider the events which are difficult to predict, the most probable is the further weakening of very soft argillite of the seam $C_{5}+C_{5}{ }^{l}$ immediate bottom due to constant moisture saturation. Therewith, it should be borne in mind that, for the most part of the crosscut length, the border rocks are presented by argillite throughout the entire arch, and here it is possible to expect an increase in vertical and oblique rock pressure.

To resist this probable process, it is recommended to strengthen argillite (in the marked areas of the mine working length), for example, by setting the resin-grouted roof bolt system along the arch contour. The roof bolts erected in the middle of the interframe space will strengthen the argillite to a depth of $2.4 \mathrm{~m}$ and, thereby, exclude the further development of rock pressure manifestations. Finally, it will be possible to judge the effectiveness of measures for strengthening the frame support of the SVC No. 1 of the seam $C_{5}$ according to the computational experiment results.

According to the research strategy formulated earlier, the second stage consists of substantiating the geomechanical model and conducting a computational experiment to calculate the SSS of the adjacent rock massif and the SVC No. 1 support in the most "problematic" areas of its maintenance, identified during mine instrumental observations. The general research algorithm involves modelling the conditions for maintaining a single mine working without taking into account the probable impact of its overworking.

The substantiation and construction of the geomechanical model have been performed in full accordance with modern rules and methods for solving such problems, taking into account the peculiarities of the mining-and-geological Western Donbas conditions $[15-18]$. Thus, the model dimensions in vertical direction $y=29.8 \mathrm{~m}$ completely include the unloading areas in the roof and bottom of the SVC No. 1 of the seam $C_{5}$, conditioned by its drivage; a horizontal dimension of $z=25 \mathrm{~m}$ provides a reflection of the high rock pressure (HRP) zones in the crosscut sides, which were also formed during its construction. The geostatic pressure at the model upper boundary is set in accordance with the average depth $H$ of mine working placement; at the lower model boundary, there is some condition of "rigid base", and at the lateral boundaries, there is a condition of "symmetry". In the cavity of the SVC No. 1 of the seam $C_{5}$, the TSYS structure frame support from the SCP-27 special profile has been modelled, which is the so-called basic option in accordance with the passport of the mine working fastening. In areas of more intense rock pressure manifestation $[19,20]$, it is recommended to strengthen the fastening structure by setting the resin-grouted roof bolt system in the interframe space of the crosscut. Fig. 2 presents one of the recommended fastening structures, which has some versatility in terms of changing the number and parameters of setting the resin-grouted roof bolts in the cross section of the SVC No. 1 of the seam $C_{5}$. Both support structures are involved in a computational experiment followed by a comparison of their SSS at the third stage.

The mechanical characteristics have been introduced into the model base according to 
geological surveys, as well as the extensive studies results of the mechanical properties of the Western Donbas rocks [21 - 23]. Relevant information for the fastening structure was taken from the reference books [24-28], and for the resin-grouted roof bolts - from the book [29].

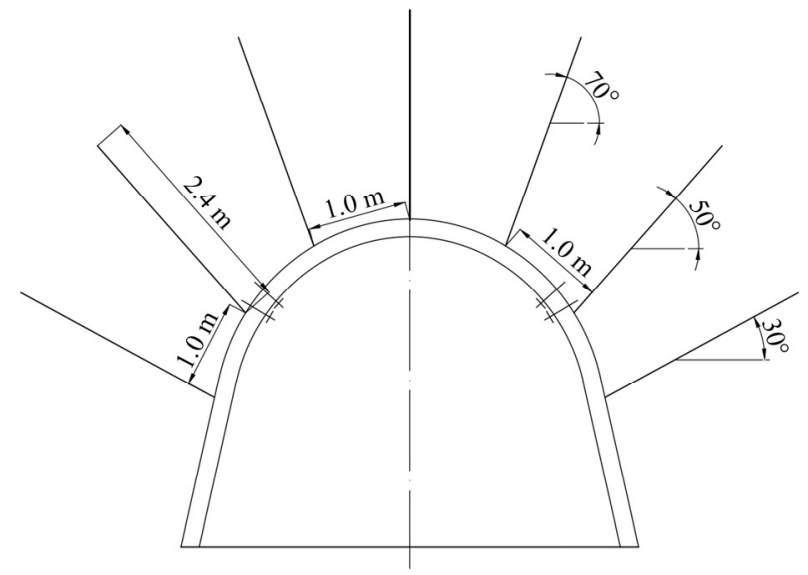

Fig. 2. The recommended scheme for fastening the SVC No. 1 of the seam $C_{5}$.

The developed geomechanical model has been tested to assess its performance and consistency with existing concepts about the displacement processes of coal-bearing massif during mining operations; the model was fully prepared for the SSS calculation [30], as well as the computational experiment has been conducted, the results analysis of which is presented below.

\section{Analysis of results}

The study of the SSS peculiarities was conducted on three main stresses components: vertical $\sigma_{y}$, horizontal $\sigma_{z}$ and stresses intensity $\sigma$; a comprehensive analysis of their distribution fields has presented the most complete pattern of mine rocks behaviour around mine working and the state of its fastening structure.

The SSS calculation of the geomechanical model (with the recommended fastening structure of the SVC No. 1 of the seam $C_{5}$ ) is displayed in Fig. 3 for all three analysed stresses components, for which the colour scale was selected so as to most clearly show the $\sigma_{y}, \sigma_{x}$ and $\sigma$ distribution in the adjacent laminal massif. To study the SSS in the fastening structure elements, it is signified separately, removing the surrounding massif from the stresses curves. The use of this technique is dictated by the large difference in the mechanical characteristics of the massif lithotypes and the support materials (they differ by an order of magnitude or more). This required a change in the stresses scale for the most reliable representation and analysis of the fastening structure SSS. The results of a more detailed study of its state are presented in a comparative analysis of the $\sigma_{y}, \sigma_{x}$ and $\sigma$ components distribution curves for the recommended and basic options of the SVC No. 1 support structures of the seam $C_{5}$. At the beginning of the analysis, the state was studied of the soft rocks laminal massif, surrounding the mine working.

According to the factor of the vertical stresses $\sigma_{y}$ action above the SVC No. 1 of the seam $C_{5}$, the formation of an arch of ultimate equilibrium is predicted with the formation of a vertical load within the frame support working resistance: the weight of the rocks inside the arch is about $220-250 \mathrm{kN} / \mathrm{m}$, which approximately corresponds to the step of $1.0 \mathrm{~m}$, when setting the frame made from the SCP-27 special profile. A very soft moisture- 
saturated argillite (compressive resistance $\sigma_{\text {compr }}=2.7 \mathrm{MPa}$ ) is located in the mine working sides, which, within its thickness, is characterized by the formation of a significant volume of unstable rocks, creating a significant lateral and oblique load on the fastening structure of the SVC No. 1 of the seam $C_{5}$. A more stable siltstone $\left(\sigma_{\text {compr }}=13.2 \mathrm{MPa}\right)$ occurs in the mine working bottom, in which the formation is predicted of limited rock volumes (up to $1.1 \mathrm{~m}$ deep and up to $2.7 \mathrm{~m}$ wide), either complete unloading $\left(\sigma_{y}=0\right)$ or insignificant tensile stresses $\sigma_{y}$ action. The existence of such an area of limiting state in the bottom of the SVC No. 1 of the seam $C_{5}$ presumes the moderate heaving development according to the factor of vertical stresses action.

$a$

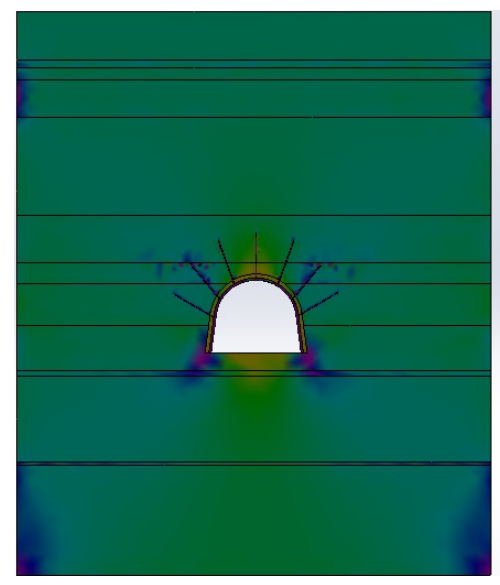

$c$

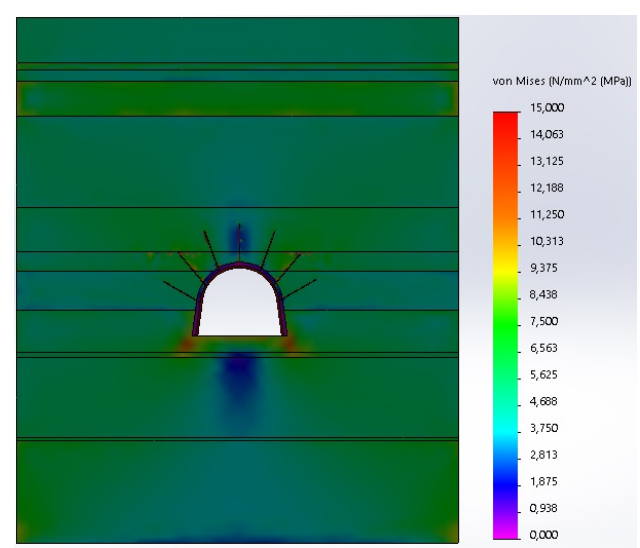

$b$

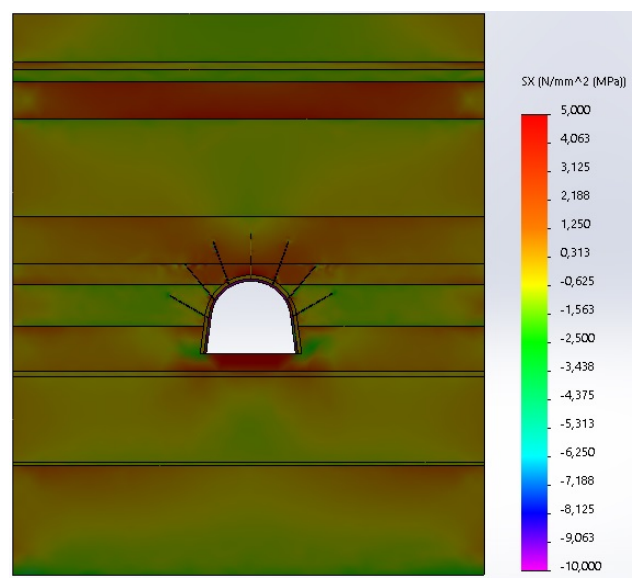

Fig. 3. Curves of the stresses components distribution in the rock massif around the SVC No. 1 of the seam $\mathrm{C}_{5}: a$ - vertical stresses $\sigma_{y}$; $b$ - horizontal stresses $\sigma_{z}$; $c$-stresses intensity $\sigma$.

The peculiarities of the horizontal stresses $y_{z}$ distribution in the mine working roof indicate the prospect of strengthening the border rocks with resin-grouted roof bolts, which will form an additional armoured and rock load-bearing structure above the arch by binding argillite and coal seam $C_{5}+C_{5}{ }^{l}$. In the mine working sides, within the thickness of a very soft argillite, the formation of rather vast areas of its limiting state (up to $3.5-4.0 \mathrm{~m}$ along the seam strike) is predicted and, as a result, the development of increased lateral load on the frame support. It is expedient here to strengthen the frame by setting the resin-grouted roof bolts in the upper part of the sides (throughout the height of soft argillite), and the lower part of the side rocks (siltstone) is quite stable and does not need additional strengthening. In the bottom rocks of the SVC No. 1 of the seam $C_{5}$, tensile stresses 
$\sigma_{z}=2-4 \mathrm{MPa}$ act; the siltstone thickness $(0.8-0.9 \mathrm{~m})$, remaining after the bottom ripping (during the mine working operation), is exposed to them, and the tension area itself extends beyond the mine working dimensions to a width of $1.7-2.0 \mathrm{~m}$. This rock volume is decisive in the heaving process development; a very thin $(0.3 \mathrm{~m})$ coal seam $C_{4}{ }^{3}$ is also joined to it. The underlying two thick siltstone layers, although they experience a bending towards the mine working cavity, but retain continuity. In general, a moderate heaving can be predicted according to the factor of the horizontal stresses $\sigma_{z}$ action.

According to the factor of the stresses intensity $\sigma$ action, the sandstone occurring in the main roof maintains stability even in a moisture-saturated state, and the formation of a limiting state is predicted in the underlying siltstone. However, this rock volume is under the conditions of so-called constrained deformation, when a holistic massif is located from all sides; it is therefore assumed that this siltstone is not involved in the vertical load formation on the SVC No. 1 support of the seam $C_{5}$. Argillite and a coal seam $C_{5}+C_{5}{ }^{l}$, occurring straight near the mine working arch, are exposed to weakening and loss of continuity even inside the unloading arch. On the sides of the arch in argillite there are vast areas of $\sigma$ concentrations over a width along the seam strike of up to $3.5-4.0 \mathrm{~m}$; they induce the formation of a significant not only vertical, but also oblique load on the support of a crosscut. Therefore, we consider it expedient to strengthen the border rocks of mine working using the resin-grouted roof bolt system. In the sides of the SVC No. 1 of the seam $C_{5}$, the same very soft argillite to a height of its thickness of $2.2 \mathrm{~m}$ contributes to the development of a significant lateral load on the frame support prop stays. To strengthen them, it is recommended to strengthen the argillite with resin-grouted roof bolts. In the lower part of the crosscut sides, there is a rather stable siltstone that is not dangerous from the point of view of increased lateral rock pressure. In the rocks of mine working bottom with a possible partial moisture saturation of siltstones, separated by a coal seam $C_{4}{ }^{3}$, moderate heaving is predicted up to $300-500 \mathrm{~mm}$.

When analysing the SSS of fastening structures, attention was primarily drawn to the resistance effectiveness to the rock pressure by the resin-grouted roof bolt system, the setting of which is recommended in potentially problematic areas of the SVC No. 1 length of the seam $C_{5}$.

The parameters of the vertical stresses $\sigma_{y}$ distribution have shown a sufficient efficiency of the scheme of resin-grouted roof bolts arrangement in order to resist to differently vectored rock pressure: the main range of their loading varies from $34-42 \%$ to $93-96 \%$ of the load-bearing capacity calculated value. The horizontal stresses $\sigma_{z}$ curve clearly indicates the formation in the mine working roof of a thrust armoured and rock structure, which, due to its thickness (at least $2.3 \mathrm{~m}$ ), is capable of taking up a rather high load of a predominantly vertical direction. The roof bolts of a flatter installation resist to the lateral rock pressure at the level of $\sigma_{z} / \sigma_{\text {yield }}=33-57 \%$, where the estimated yield limit of steel of the roof-bolt reinforcement is designated through $\sigma_{\text {yield }}$. According to the factor of the stress intensity $\sigma$ action, the degree of the roof bolts loading in the main range of $40-93 \%$ has been determined.

In general, the components distribution parameters confirm the expediency of setting the resin-grouted roof bolts to strengthen the frame support: each roof bolt performs its function (depending on the coordinates of its location) in unloading the frame support from the increased differently vectored rock pressure acting along the SVC No. 1 contour of the seam $C_{5}$.

The evidence of maintaining mine working in a stable state with the recommended fastening structure is very important, but does not answer the question: is it possible that with the existing (basic) fastening structure, mine working will also be in a satisfactory operational state? Partially, the answer to this question has already been given when monitoring the SVC No. 1 state of the seam $C_{5}$ by measuring the residual section of mine 
working. When performing measurements, the least stable areas of the crosscut have been identified, which can be potentially dangerous in terms of intensification of the rock pressure manifestations for various geomechanical reasons, including the factor of overworking the protecting pillar of the seam $C_{5}$. Therefore, a comparative analysis has been performed of the state parameters of the recommended and basic fastening structures, which was based on the curves of the main SSS components distribution along the frame support contour.

The comparative analysis results of the vertical stresses $\sigma_{y}$ distribution are presented in the form of graphs (Fig. 4) of the maxima $\sigma_{y}$ distribution in each cross section of the SCP frame.

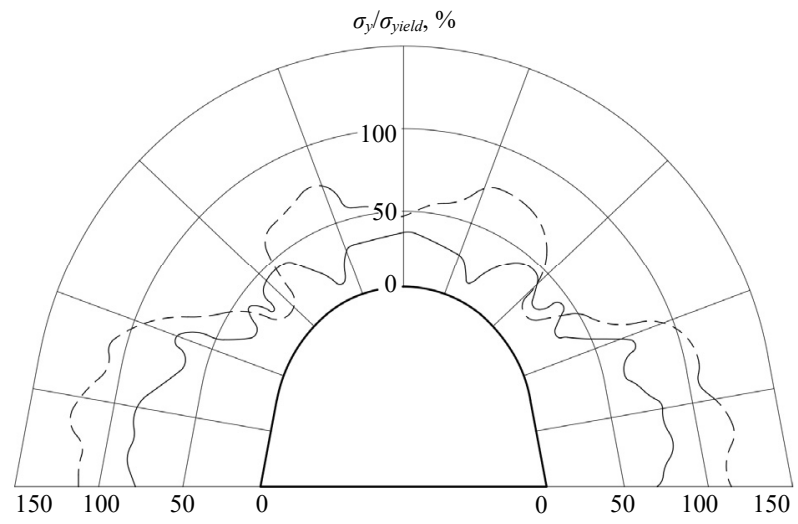

Fig. 4. Distribution of relative vertical stresses $\sigma_{y} / \sigma_{\text {yield }}$ along the frame support contour: $\longrightarrow$ recommended structure; - - - basic structure.

The relative indicator $\sigma_{y} / \sigma_{\text {yield }}$ gives a quantitative assessment (in percentage terms) of how close the vertical stresses value $\sigma_{y}$ is to the estimated yield limit $\sigma_{\text {yield }}$ of SCP steel, which fixes the occurrence of the limiting state in a particular area of the frame support contour.

The following differences in the indicator $\sigma_{y} / \sigma_{\text {yield }}$ distribution parameters between the recommended and basic fastening structures have been determined in the frame cap board. In the arch keystone, the indicator $\sigma_{y} / \sigma_{\text {yield }}$ reaches maximum values of $26 \%$ in the recommended structure, and then in the area with a width of up to $2.1-2.3 \mathrm{~m}$, it slightly decreases to $20-23 \%$. Somewhere at the same length of the arch central part and the basic structure, the range of change $\sigma_{y} / \sigma_{\text {yield }}$ is $37-69 \%$ with the maximum values located closer to the peripheral part of the cap board.

The data presented indicate the underloaded state of the cap board for both compared structures, but the degree of unloading of the recommended option is by $1.42-3.45$ times higher than for the basic option. Obviously, the decisive role here is played by the protective function of the armoured and rock arch formed above the crosscut with a set of resin-grouted roof bolts.

Near the yielding joists of the frame and along their length, the indicator $\sigma_{y} / \sigma_{\text {yield }}$ was even slightly lower in the basic structure compared to the recommended one. A higher degree of the yielding joists unloading with increased loading of the frame cap board indirectly indicates their insufficiently effective work to ensure yielding mode in case of increased rock pressure.

In the prop stays of the frame support, starting from their upper curvilinear part, there is a stable excess of the indicator $\sigma_{y} / \sigma_{\text {yield }}$ for the basic structure compared to the recommended one. Thus, the excess of the indicator $\sigma_{y} / \sigma_{\text {yield }}$ is $1.47-1.98$ times in the curvilinear part of the prop stay, but the vertical stresses $\sigma_{y}$ value does not exceed the 
estimated yield limit $\sigma_{\text {yield }}$ of SCP steel. That is, despite the increased values $\sigma_{y} / \sigma_{\text {yield }}$ in the basic structure, the plastic state is not observed in the curvilinear part of the prop stays.

A different situation is in the rectilinear part of the prop stay of the basic option of the crosscut fastening structure. Here, the indicator $\sigma_{y} / \sigma_{\text {yield }}$ exceeds in a stable manner the value of $100 \%$, varying in the range of $105-120 \%$. This means a transition of the entire rectilinear part of the prop stays to the limiting and superlimiting state according to the factor of the vertical stresses $\sigma_{y}$ action; the plastic bends of prop stays with the subsequent loss of a stable form are very probable here. In relation to the recommended structure, the indicator $\sigma_{y} / \sigma_{\text {yield }}$ is exceeded by $1.54-1.90$ times.

Summing up the comparative analysis results of the vertical stresses $\sigma_{y}$ parameters distribution, it can be concluded that the recommended structure provides not only a decrease in the component $\sigma_{y}$ (by $1.42-3.54$ times in the cap board, by $1.47-1.98$ times in the prop stays), but also a prelimiting state of the frame along its entire contour.

For horizontal stresses $\sigma_{z}$, a comparative analysis has led to the following results, shown in the graphs of Fig. 5.

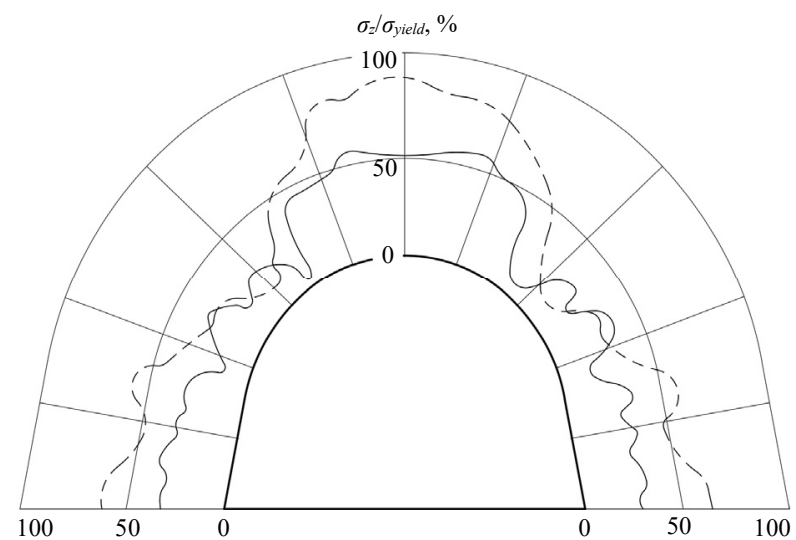

Fig. 5. Distribution of relative horizontal stresses $\sigma_{z} / \sigma_{\text {yield }}$ along the frame support contour: recommended structure; - - - basic structure.

In the cap board of the frame support almost along its entire length, the value $\sigma_{z}$ in the basic structure invariably exceeds that for the recommended fastening structure of the SVC No. 1 of the seam $C_{5}$. This confirms the indicator values of $\sigma_{z} / \sigma_{\text {yield }}=48-83 \%$ in the basic option as compared to $41-54 \%$ in the recommended option: in the main part of the cap board length, the increase in horizontal stresses is $1.32-1.80$ times.

Nevertheless, the maxima $\sigma_{z}$ in the cap board of the basic structure do not exceed the permissible values $\sigma_{\text {yield }}$, which indicates the absence of plastic state areas and its stability. The same conclusion refers to the prop stays of the frame support in the basic option: the indicator $\sigma_{z} / \sigma_{\text {yield }}$ varies in the range of $28-58 \%$. But, in relation to the recommended structure, an increase in $\sigma_{z}$ occurs up to $1.67-2.07$ times.

The above data indicate a sufficiently effective work of the armoured and rock arch to protect the frame support from the rock pressure manifestations. But, according to the factor of horizontal stress $\sigma_{z}$ action, the frame, as an independent type of support, does not need in setting a set of resin-grouted roof bolts along the contour of the crosscut.

The final conclusion about the necessity to strengthen the frame support of the SVC No. 1 of the seam $C_{5}$ with a system of resin-grouted roof bolts (in potentially dangerous 
areas of the crosscut) has been made on the basis of a comparative analysis of the stresses intensity $\sigma$ distribution along the mine working contour, which is shown in Fig. 6 as an indicator $\sigma / \sigma_{\text {yield }}$.

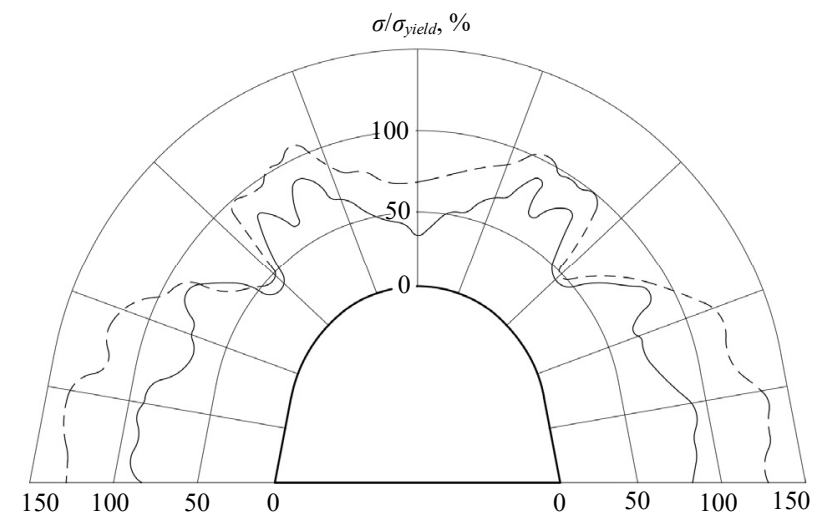

Fig. 6. Distribution of the relative intensity of stresses $\sigma / \sigma_{\text {yield }}$ along the frame support contour: — recommended structure; - - -basic structure.

The cap board of the frame support, as expected, is more loaded in the basic option compared to the recommended one. In the arch central part with a length of $1.5-1.6 \mathrm{~m}$, the indicator $\sigma / \sigma_{\text {yield }}$ varies in the range of $54-75 \%$ compared to $22-52 \%$ in the recommended fastening structure; an increase in $\sigma$ was $1.44-2.45$ times. As it approaches the peripheral areas of the cap board, the indicator $\sigma / \sigma_{\text {yield }}$ increases to $87-96 \%$, that is, it approaches the estimated yield limit of SCP steel and its limiting state. In the recommended structure, the stresses intensity by $1.22-1.64$ times lower and this is conditioned by the protective effect of the armoured and rock structure around the crosscut. At the same time, the state of the frame cap board approaches the limiting one, but does not reach it.

Near the yielding joists of the frame support, there is a fairly synchronous (for both options) decrease in $\sigma$ and further gradual increase in the curvilinear part of the prop stays until occurrence of the limiting state $\left(\sigma / \sigma_{\text {yield }}=100 \%\right)$. In the rectilinear part of the prop stays, the indicator $\sigma / \sigma_{\text {yield }}$ exceeds $100 \%$ in a stable manner, varying in the range of $113-137 \%$, and characterizes all round occurrence of the limiting and superlimiting state. This contributes to losing the stable form by the prop stays and to activation of their convergence with a significant decrease in the residual area of the cross section of crosscut.

In general, a comparative analysis of the frame support state in the basic and recommended options has revealed a number of advantages of the recommended one:

- despite the absence of a limiting state in the cap board (but only approaching to it), the recommended option creates a significant safety factor by reducing the stresses intensity by 1.22 - 2.45 times;

- in the basic option, the entire rectilinear part of the prop stays changes into a limiting state, and the recommended option excludes it, providing a decrease of $\sigma$ by $1.52-1.88$ times;

- the positive effect of the recommended fastening structure is ensured by the performance of the protective function by the armoured and rock arch-shaped system formed by a set of resin-grouted roof bolts with the right choice of parameters for their setting.

The practical significance of the obtained results is as follows. The mine instrumental observations analysis has proved the satisfactory state of the SVC No. 1 of the seam $C_{5}$ before to start its overworking during the protecting pillar extraction along the seam $C_{6}$. Nevertheless, a number of so-called problem areas along the mine working length (PK3 - 
PK5, PK31 - PK33, PK98 - PK101 and PK109 - PK111) have already been identified, which can lose the required operating parameters when the rock pressure manifestations caused by overworking are intensified. In this regard, practical recommendations have been developed so as that to block the negative influence of the mine working overwork by increasing the resistance reaction of its fastening structure:

- according to existing studies of similar mining-and-geological Western Donbas conditions with a parting thickness of $25-30 \mathrm{~m}$, the "residual" overwork effect in the underlying seam can be manifested through the rock pressure intensification up to $1.2-1.4$ times;

- the recommended fastening structure of the SVC No. 1 of the seam $C_{5}$ provides an ignorance factor of the cap board load-bearing capacity up to 2.45 times, and of its prop stays - up to 1.88 times, which completely covers other poorly predicted factors of the rock pressure intensification.

The fastening structure scheme, which is recommended in potentially dangerous areas of the SVC No. 1 of the seam $C_{5}$ is presented in Fig. 2 and substantiated based on the computational experiments results. The frame support has the same parameters as before, and in the middle of the interframe space seven roof bolts are set symmetrically with respect to the crosscut axis. The roof bolts arrangement along the contour is uniform every $1.0 \mathrm{~m}$, starting from the central vertical roof bolt (Fig. 7). The gradient angle of roof bolts decreases from $90^{\circ}$ in the arch keystone to $30^{\circ}$ in its spring in accordance with the scheme. Roof bolt length is $2.4 \mathrm{~m}$.

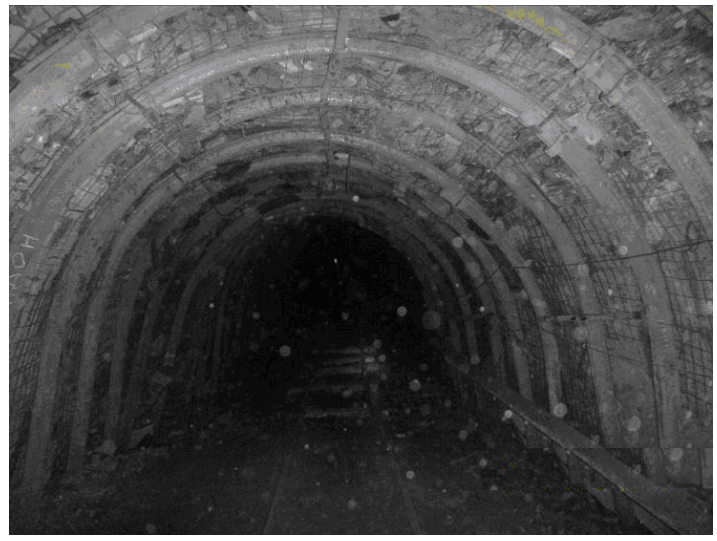

Fig. 7. An illustration of a mine working state according to the recommended fastening scheme.

The recommended parameters of the fastening structure provide repair-free maintenance of the SVC No. 1 of the seam $C_{5}$ for the entire exploitation period, taking into account the overworking along the seam $C_{6}$.

\section{Conclusions}

Based on the experience study of maintaining mine workings being overworked in the Western Donbas mines, as well as the modern studies of the parting rocks stability, the expediency has been substantiated for combining the methods of mine instrumental observations and computational experiments to develop adequate and reliable recommendations for maintaining mine working being overworked.

Mine research has determined the satisfactory performance characteristics of the SVC No. 1 of the seam $C_{5}$ for the period before to start its overworking: convergence of the roof 
and the bottom of mine working, as well as its sides maintain permissible gaps and distances according to the requirements of safety rules; the area value of the residual section is more than by 1.5 times higher than the minimum permissible value according to ventilation conditions.

The SSS analysis of the adjacent massif made it possible to predict the formation of a significant differently vectored rock pressure onto the support, to resist to which the recommendations have been developed for strengthening the fastening structure; the recommendations expediency has been confirmed by the analysis results of its main elements SSS - the cap board, prop stays and a set of resin-grouted roof bolts.

Due to the strengthening of the basic support, the ignorance factor of the load-bearing capacity completely covers not only the probable overwork effect, but also other possible factors of the rock pressure intensification. The developed recommendations are used when mining out the seam $C_{6}$ reserves in M.I. Stashkova Mine in the Western Donbas.

The authors express their gratitude to the management of DTEK Coal Unit for their help in organizing the experimental research.

\section{References}

1. Sribna, Y., Trokhymets, O., Nosatov, I., \& Kriukova, I. (2019). The globalization of the world coal market - contradictions and trends. E3S Web of Conferences, 123, 01044. https://doi.org/10.1051/e3sconf/201912301044

2. Kovalevska, I., Barabash, M., \& Snihur, V. (2018). Development of a research methodology and analysis of the stress state of a parting under the joint and downward mining of coal seams. Mining of Mineral Deposits, 12(1), 76-84. https://doi.org/10.15407/mining12.01.076

3. Barabash, M.V. (2017). Intensyfikatsiia hirnychykh robit pry sumisnomu vidpratsiuvanni vuhilnykh plastiv z urakhuvanniam zon znemitsnennia mizhplastia. PhD Thesis. Dnipro, Ukraine: NHU.

4. Bondarenko, V., Kovalevs'ka, I., \& Ganushevych, K. (2014). Progressive Technologies of Coal, Coalbed Methane, and Ores Mining. The Netherlands: CRC Press/Balkema, 521. https://doi.org/10.1201/b17547

5. Bondarenko, V., Kovalevska, I., Symanovych, H., Barabash, M., \& Snihur, V. (2018). Assessment of parting rock weak zones under the joint and downward mining of coal seams. E3S Web of Conferences, (66), 03001. https://doi.org/10.1051/e3sconf/20186603001

6. Barabash, M. (2016). Analiz sostoyaniya nadrabotannogo i podrabotannogo mezhduplast'ya smezhnykh plastov pri ikh sovmesnoy otrabotke $\mathrm{v}$ niskhodyashchem poryadke. Rozrobka Rodovyshch, 10(2), 34-39.

7. Pivnyak, G., Samusia, V., Oksen, Y., \& Radiuk, M. (2015). Efficiency increase of heat pump technology for waste heat recovery in coal mines. New Developments in Mining Engineering, 1-4. https://doi.org/10.1201/b19901-2

8. Malkowski, P., Majcherczyk, T., \& Niedbalski, Z. (2006). Speed of Roof Rock Separation and a Type of Working, Äôs Support. International Mining Forum 2006, New Technological Solutions in Underground Mining, 39-47. https://doi.org/10.1201/noe0415401173.ch6

9. Witek, M., \& Prusek, S. (2016). Numerical calculations of shield support stress based on laboratory test results. Computers and Geotechnics, (72), 74-88. https://doi.org/10.1016/j.compgeo.2015.11.007

10. Lozynskyi, V., Saik, P., Petlovanyi, M., Sai, K., \& Malanchuk, Z. (2018). Analytical Research of the Stress-Deformed State in the Rock Massif around Faulting. International Journal of $\begin{array}{lllll}\text { Engineering } \quad \text { Research } & \text { 7n }\end{array}$ https://doi.org/10.4028/www.scientific.net/jera.35.77

11. Bondarenko V., Symanovych, H., Kicki J., Barabash, M., Salieiev, I. (2019). The influence of rigidity of the collapsed roof rocks in the mined-out space on the state of the preparatory mine 
workings. Mining of Mineral Deposits, 13(2), 27-33. https://doi.org/10.33271/mining13.02.027

12. Kovalevska, I., Samusia, V., Kolosov, D., Snihur, V., \& Pysmenkova T. (2020). Stability of the overworked slightly metamorphosed massif around mine working. Mining of Mineral Deposits, 14(2):43-52. https://doi.org/10.33271/mining14.02.043

13. Kovalevska, I., Barabash, M., Husiev, O., \& Snihur, V. (2018). Interaction of deformationstrength characteristics of the support load-bearing elements in the preparatory workings. E3S Web of Conferences, (60), 00002. https://doi.org/10.1051/e3sconf/20186000002

14. Kyrychenko, Y., Samusia, V., \& Kyrychenko, V. (2012). Software development for the automatic control system of deep-water hydrohoist. Geomechanical Processes During Underground Mining Proceedings of the School of Underground Mining, 81-86. https://doi.org/10.1201/b13157-14

15. Bondarenko, V., Kovalevs'ka, I., \& Fomychov, V. (2012). Features of carrying out experiment using finite-element method at multivariate calculation of "mine massif - combined support" system. Geomechanical Processes During Underground Mining - Proceedings of the School of Underground Mining, 7-14. http://dx.doi.org/10.1201/b13157-3

16. Inkin, O., Tishkov, V., Dereviahina, N., \& Sotskov, V. (2018). Integrated analysis of geofiltrational parameters in the context of underground coal gasification relying upon calculations and modeling. E3S Web of Conferences, (60), 00035.

17. Timoshuk, V., Tishkov, V., Inkin, O., \& Sherstiuk, E. (2012). Influence of coal layers gasification on bearing rocks. Geomechanical Processes During Underground Mining - Proceedings of the School of Underground Mining, 109-113. https://doi.org/10.1201/b13157-19

18. Kovalevska, I., Symanovych, G., \& Fomychov, V. (2013). Research of stress-strain state of cracked coal-containing massif near-the-working area using finite elements technique. Annual ScientificTechnical Collection - Mining of Mineral Deposits, 159-163. http://dx.doi.org/10.1201/b16354-28

19. Bondarenko, V., Hardygora, M., Symanovych, H., Sotskov, V., \& Snihur, V. (2016). Numerical methods of geomechanics tasks solution during coal deposits' development. Mining of Mineral Deposits, 10(3), 1-12. https://doi.org/10.15407/mining10.03.001

20. Walentek, A., Janoszek, T., Prusek, S., \& Wrana, A. (2019). Influence of longwall gateroad convergence on the process of mine ventilation network-model tests. International Journal of Mining Science and Technology, 29(4), 585-590. https://doi.org/10.1016/j.ijmst.2019.06.013

21. Usachenko, B.M. (1979). Svoystva porod i ustoychivost' gornykh vyrabotok. Kyiv: Naukova dumka, 136.

22. Usachenko, B.M., Kirichenko, V.Ya., \& Shmigol', A.V. (1992). Okhrana podgotovitel'nykh vyrabotok glubokikh gorizontov shakht Zapadnogo Donbassa. Moskva: TsNIEIugol', 168.

23. Usachenko, B.M., Cherednichenko, V.P., \& Golovchanskiy, I.Ye. (1990). Geomekhanika okhrany vyrabotok v slabometamorfizirovannykh porodakh. Kyiv: Naukova dumka, 144.

24. Malkowski, P., \& Ostrowski, L. (2019). Convergence monitoring as a basis for numerical analysis of changes of rock-mass quality and hoek-brown failure criterion parameters due to longwall excavation. Archives of Mining Sciences, 64(1), https://doi.org/10.24425/ams.2019.126274

25. Pisarenko, G.S. (1979). Soprotivlenie materialov. Kyiv: Vyshcha shkola, 696.

26. Anur'ev, V.I. (1980). Spravochnik konstruktora-mashinostroitelya. Tom 1. Moskva: Mashinostroenie, 728.

27. Geleskul, M.N., \& Karetnikov, V.N. (1982). Spravochnik po krepleniyu kapital'nykh $i$ podgotovitel'nykh gornykh vyrabotok. Moskva: Nedra, 479.

28. Koval, V., Mikhno, I., Trokhymets, O., Kustrich, L., \& Vdovenko, N. (2020). Modeling the interaction between environment and the economy considering the impact on ecosystem. E3S Web Conferences, (166), 13002. https://doi.org/10.1051/e3sconf/202016613002

29. Mel'nikov, N.I. (1980). Ankernaya krep'. Moskva: Nedra, 252.

30. Malashkevych, D., Sotskov, V., Medyanyk, V., \& Prykhodchenko, D. (2018). Integrated evaluation of the worked-out area partial backfill effect of stress-strain state of coal-bearing rock $\begin{array}{llll}\text { mass. State } & \text { Solid }\end{array}$ https://doi.org/10.4028/www.scientific.net/SSP.277.213 